\title{
Bacteriological Profiles of Pus with Antimicrobial Sensitivity Pattern at a Teaching Hospital in Vikarabad
}

\author{
Qader Ahmed Jalily, G. Sasikala* and and Usha Rani Ramavath
}

Department of Microbiology, Mahavir Institute of Medical Sciences, \#2-4-40, Shivareddypet, Vikarabad, Ranga Reddy - 501 101, Telangana, India

*Corresponding author

\section{A B S T R A C T}

\section{Keywords}

Bacteriological profile, Pus,

Pyogenic infection, Antimicrobial resistance,

Staphylococcus aureus, Methicillin

Resistant

Staphylococcus aureus (MRSA), Extended-spectrum beta-lactamase (ESBL)

Article Info

Accepted:

12 June 2019

Available Online:

10 July 2019
Pyogenic infections are one of the major complications of surgery and trauma. Both aerobic and anaerobic bacteria have been implicated in these infections which commonly occur under hospital environment resulting in significant morbidity, prolonged hospitalization and huge economic burden. Hence periodical monitoring of bacterial profile and their antibiotic susceptibility pattern is important. A retrospective study was undertaken to identify the microbial profile with their antibiogram among the pus culture isolates in a teaching tertiary care hospital from January 2018 to December 2018. 171 pus culture samples processed at the microbiology lab were analyzed. The isolates from positive pus culture were identified by standard protocols and antimicrobial susceptibility patterns were identified by CLSI guidelines. Positive pus cultures were obtained in $52 \%$ (89/171). Gram positive bacteria accounted for $46.2 \%$ (43), Gram negative bacteria $53.8 \%$ (50) and Candida spp $1.01 \%$ (1) with predominance of $S$. aureus $30 \%$ (28) followed by K. pneumoniae $18 \%$ (17) and E. coli $17 \%$ (16). $39.5 \%$ of $S$. aureus was MRSA and $100 \%$ sensitive to vancomycin. $88 \%$ of $E$. coli and $53 \%$ of K. pneumoniae were ESBL producers and $100 \%$ sensitive to meropenam.

\section{Introduction}

Pyogenic infections are one of the major complications of surgery and trauma. The factors which contribute to pyogenic infections include pre-existing illness, duration of operation, wound class and wound contamination (Pushpalatha Hanumanthappa et al., 2016). These infections are characterized by local inflammation, leading to pus formation. They are generally caused by one of the pyogenic bacteria, which produce the accumulation of dead leukocytes and infectious agent commonly known as pus (Koneman et al., 2005). Pyogenic infections may be endogenous or exogenous. The human skin and soft tissue infections (SSTIs) are caused by microorganisms during or after 
trauma, burn injuries, and surgical procedures (Cogen et al., 2008). Pyogenic infections may be polymicrobial or monomicrobial in nature (Jeffery stone and Paul Cianci, 1997). Both aerobic and anaerobic bacteria have been isolated from wound infections which commonly occur under hospital environment resulting in significant morbidity, prolonged hospitalization and huge economic burden (Scalise et al., 2015). Most common organisms encountered are Staphylococcus aureus, Klebsiella spp., Escherichia coli, Pseudomonas spp., Proteus spp., Enterococci spp (Krige and Beckingham, 2001).

Antibiotic resistance among bacteria is becoming an increasingly serious problem throughout the world. It is said that evolution of bacteria towards multidrug resistance is unavoidable because it represents a particular aspect of the general evolution of bacteria that is un-stoppable (Courvalin, 2005). Antibiotic resistance emerges commonly when patients are treated with empiric antimicrobial drugs. Monitoring of resistance patterns in the hospital is needed to overcome these difficulties and to improve the outcome of serious infections (El-Azizi et al., 2005). During the last few decades, multidrugresistant Gram-negative bacterial strains such as Acinetobacter baumannii, E. coli, Klebsiella pneumoniae, Pseudomonas aeruginosa and Gram-positive methicillinresistant Staphylococcus aureus (MRSA) were increasingly associated with pus infections under hospital settings due to extensive overuse and inadequate dose regimen of antibiotics (Iredell et al., 2016).

There is a need of regular analysis of the profile and antibiogram of organisms isolated and the results need to be communicated to clinician. So, the present study was undertaken to evaluate aerobic bacteriological profile along with their susceptibility to antimicrobial agents.
The main aim and objectives of this study includes to isolate and identify pathogenic bacteria from pus samples. And also to determine the antibiotic resistance profile of the isolates. As a baseline study to formulate hospital antibiotic policy and empirical treatment.

\section{Materials and Methods}

Type of study: Retrospective study

Duration of the study: January 2018 to December 2018

Place of the study: Department of Microbiology, Mahavir Institute of Medical Sciences

\section{Inclusion criteria}

Laboratory records of patients with bacterial isolates from pus samples tested for antibiotic susceptibility during the period January 2018 - December 2018.

\section{Exclusion criteria}

1. Laboratory records with incomplete data.

2. Laboratory records with no bacterial growth.

3. Laboratory records with bacterial isolates not tested for antibiotic susceptibility.

\section{Sample processing}

In our Microbiology laboratory, all pus samples collected by sterile swabs and sterile syringe aspiration are processed by inoculation on blood agar and Mac Conkey agar. Inoculated plates and the broth are incubated at $37{ }^{\circ} \mathrm{C}$ overnight. Culture plates checked for the bacterial growth next day. All bacterial isolates are examined for colony characteristics, Gram staining, motility and biochemical tests. Biochemical tests employed were oxidase, catalase, nitrate, urea 
hydrolysis, citrate utilization, sugar fermentation, indole production test and $\mathrm{H}_{2} \mathrm{~S}$ production on TSI agar (Collee et al., 2008).

\section{Antimicrobial susceptibility testing}

In our microbiology laboratory, Antibiotic sensitivity testing was done by Kirby-Bauer disc diffusion method on Mueller-Hinton agar, as per Clinical and Laboratory Standards Institute guidelines (Bauer et al., 1966; Clinical and Laboratory Standards Institute 2016). Briefly, inocula were prepared for each bacterial isolate by adjusting the turbidity to 0.5 McFarland standard and spread on Muller-Hinton agar plates. Standard ATCC strains were used as control. Antibiotic discs were procured from HiMedia, Mumbai, India.

The antibiotics that were included for testing were Amikacin $(30 \mu \mathrm{g})$, amoxicillinclavulanic acid $(30 \mu \mathrm{g})$, azithromycin $(30 \mu \mathrm{g})$, aztreonam $(30 \mu \mathrm{g})$, ceftazidime $(30 \mu \mathrm{g})$, ceftriaxone $(30 \mu \mathrm{g})$, cefuroxime $(30 \mu \mathrm{g})$, cefazolin $(30 \mu \mathrm{g})$, cefoxitin $(30 \mu \mathrm{g})$, ceftazidime-clavulanic acid $(30 / 10 \quad \mu \mathrm{g})$ ciprofloxacin $(5 \mu \mathrm{g})$, clindamycin $(2 \mu \mathrm{g})$, gentamicin $(10 \mu \mathrm{g}), \quad$ linezolid $(30 \mu \mathrm{g})$, meropenem $(10 \mu \mathrm{g})$, Penicillin-G (10 units), piperacillin-tazobactam

Trimethoprim-Sulphamethoxazole

$(1.25 / 23.75 \mu \mathrm{g}) \quad$ tetracycline $(30 \mu \mathrm{g})$, Tobramycin $(10 \mu \mathrm{g})$ and vancomycin $(30 \mu \mathrm{g})$.

Detection of MRSA (Methicillin Resistant Staphylococcus aureus) and ESBL (Extended Spectrum Beta-lactamases) production was done according to CLSI guidelines. (Clinical and Laboratory Standards Institute 2016)

\section{Statistical analysis}

The data was expressed as percentages and analyzed by SPSS version 21.p value $<0.5$ was considered significant.

\section{Results and Discussion}

Out of 171 pus culture samples, 89 (52\%) gave positive result (Fig. 1). From 89 culture positive samples, $41(46 \%)$ were males and 48 (54\%) were females (Table 1). Among the department wise distribution of positive pus culture isolates, Surgery showed maximum culture positivity 38 (43\%) followed by Orthopaedics 32 (36\%) and Gynaecology 10 (11\%) (Table 2). Of the 89 positive pus culture isolates, 83 yielded monomicrobial bacterial isolates, 5 yielded polymicrobial bacterial isolates and 1 fungal isolate. So a total of 94 organisms were isolated. Among 93 bacterial isolates, Gram positive and Gram negative bacteria constituted $43(46.2 \%)$ and $50(53.8 \%)$ respectively.

The predominant bacterial isolate was $S$. aureus 28 (30\%), followed by K. pneumonia 17 (18\%), E. coli 16 (17\%), Pseudomonas aeroginosa 12 (12\%), Streptococcus pyogenes $8(8 \%)$, Staphylococcus epidermidis 6(6\%), Citrobacter spp 3(3\%), Proteus vulgaris 2 (2\%) and Enterococcus sp. 1(1\%).The 1 fungal isolate was Candida non albicans spp (1.01\%) (Fig. 2). All Gram positive isolates showed $100 \%$ sensitivity to vancomycin. MRSA was found in 11 (39\%) and MR CONS in $2(33 \%)$ (Fig. 3). S. aureus showed a high resistance to penicillin (96\%), Trimethoprim-Sulphamethoxazole (68\%) and ciprofloxacin (57\%) (Table 3). All Gram negative isolates were sensitive to meropenem $(100 \%)$. Only $5(10 \%)$ of Gram negative isolates showed sensitivity to TrimethoprimSulphamethoxazole. Among Enterobacteriaceae (38/93), 25 (65.8\%) (Fig. 4) isolates were resistant to 3rd generation cephalosporins. ESBL production in $K$. pneumoniae 9 (53\%), E. coli was $14(88 \%)$, and Citrobacter sp. 2 (67\%). Enterobacteriaceae isolates showed a sensitivity pattern of $37(97.3 \%)$ to piperacillin-tazobactum, $33(86.84 \%)$ to both amikacin and tobramycin, and $31(81.57 \%)$ to 
ciprofloxacin (Table 4). The non-fermenter $P$. aeroginosa showed high sensitivity to piperacillin-tazobactum (100\%), amikacin (92\%), gentamicin (92\%), aztreonam and ceftazidime ( $83 \%$ each).

In our study, age of the study group ranged from 5 to 85 years, with mean age of 45 years. Among these, $46 \%$ were males, while $54 \%$ were females. In another study conducted by Subha $M$. and Meerah Srinivasagam (2018), 56.62\% were males and $43.38 \%$ were females.

A total of 171 specimens were received in our study, predominant isolate obtained from pus samples was Staphylococcus aureus 28 (30\%) followed by Klebsiella pneumoniae 17(18\%). In another study conducted Pushpalatha Hanumanthappa et al., (2016) at a teaching hospital in South India, Staphylococcus aureus was the most frequent isolate (43.6\%) followed by Klebsiella sp (17.3\%). In another similar study done by Khanam et al., (2018), Staphylococcus aureus (25\%) was the most frequent isolates. Similar findings were observed among pus isolates in another study conducted by Neelima et al (34.3\%) (2013). However, Agnihotri N et al (2004) found it to be second most common pathogen after Pseudomonas spp. Though $S$. aureus was the predominant organism, gram-positive cocci accounted for $46.2 \%$ of the total isolates, $53.8 \%$ being Gram negative bacilli (GNB). This higher prevalence of GNB in pyogenic infections has been supported by a study done by Ghosh et al., (2009).

Other studies showed different distribution of bacterial isolates which may be attributed to the differences in study design, geographical location and climate conditions.

In our study, Gram-positive isolates showed maximum susceptibility to vancomycin and linezolid while Gram-negative isolates were most susceptible to meropenem, piperacillintazobactam, Amikacin, tobramycin and ciprofloxacin. Similar results were obtained in another study conducted by Perween et al., (2018). In a study conducted by Rao et al., (2014), Gram positive isolates were found most susceptible to Vancomycin (100\%) followed by Levofloxacin $(76.92 \%)$ and Oxacillin (73.07\%). Gram Negative Bacilli were susceptible to Imipenam (80\%), Aztreonam (80\%), Piperacillin + Tazobactum (80\%), Levofloxacin (80\%).

In the present study 11 (39\%) of S. aureus was MRSA which is similar to the finding of Mohanty et al., (2004) (38.56\%).Whereas Pushpalatha Hanumanthappa et al., (2016) reported a higher incidence of MRSA $(53.96 \%)$. All the isolates of S. aureus were sensitive to vancomycin as comparable with Sujatha et al., (2016). The ESBL producing Enterobacteriaceae in our study was $65.8 \%$ of which $K$. pneumoniae (53\%) and E. coli was (88\%), which is higher than a recent study done by Subha and Meerah Srinivasagam (2018) whose ESBL detection rate was $42.10 \%$ of which $E$. coli were $23.61 \%$ and $K$. pneumoniae $25 \%$. According to a study done in Nepal (Shrestha et al., 2011), prevalence of ESBL was much lower at $18 \%$. The higher prevalence of ESBL in our study and increased resistance to $3^{\text {rd }}$ generation cephalosporins, $\quad \beta$-lactam- $\quad \beta$-lactamase inhibitors, co-trimoxazole is a matter of great concern.

Periodic monitoring of susceptibility pattern need to be carried out in each hospital settings so as to detect the actual burden of antibiotic resistance in organisms and prevent the emergence of drug resistant organisms by judicial use of antibiotics. Each hospital should take proactive steps in setting up antibiotic policy guidelines and constitute a hospital infection committee to monitor the emergence of drug resistance and should 
implement standard precautions among health care personnel. In most developing countries like India, patients are able to obtain antimicrobials over the counter with or without prescription from a medical practitioner. This could be another reason for high level of resistance among the isolates in the present study (Table 5).

Table.1 Age and gender distribution of study population $(\mathrm{n}=89)$

\begin{tabular}{|l|l|l|l|}
\hline Age Group & Male & Female & Total \\
\hline$<20$ years & 10 & 6 & 16 \\
\hline $20-40$ & 14 & 26 & 40 \\
\hline $40-60$ & 9 & 12 & 21 \\
\hline$>60$ & 8 & 4 & 12 \\
\hline TOTAL & 41 & 48 & 89 \\
\hline
\end{tabular}

Table.2 Ward wise distribution of pus culture isolates $(n=89)$

\begin{tabular}{|l|l|l|}
\hline S. No & Ward & Number \\
\hline $\mathbf{1}$ & Surgery & $\mathbf{3 8}(\mathbf{4 3} \%)$ \\
\hline $\mathbf{2}$ & Orthopaedic & $\mathbf{3 2}(\mathbf{3 6} \%)$ \\
\hline $\mathbf{3}$ & Gynaecology & $\mathbf{1 0}(\mathbf{1 1} \%)$ \\
\hline $\mathbf{4}$ & ENT & $\mathbf{5}(\mathbf{6} \%)$ \\
\hline $\mathbf{5}$ & Medicine & $\mathbf{3}(\mathbf{3} \%)$ \\
\hline $\mathbf{6}$ & Dermatology & $\mathbf{1} \mathbf{( 1 \% )}$ \\
\hline & Total & $\mathbf{8 9}(\mathbf{1 0 0} \%)$ \\
\hline
\end{tabular}

Table.3 Antibiotic sensitivity pattern of gram positive cocci

\begin{tabular}{|c|c|c|c|c|c|c|c|c|}
\hline \multirow[t]{2}{*}{ Antibiotics } & \multicolumn{2}{|c|}{$\begin{array}{l}\text { Staphylococcus } \\
\text { aureus }(n=28)\end{array}$} & \multicolumn{2}{|c|}{$\begin{array}{l}\text { Staphylococcus } \\
\text { epidermidis }(n=6)\end{array}$} & \multicolumn{2}{|c|}{$\begin{array}{l}\text { Streptococcus } \\
\text { pyogenes }(n=8)\end{array}$} & \multicolumn{2}{|c|}{$\begin{array}{l}\text { Enterococcus } \\
\operatorname{sp}(n=1)\end{array}$} \\
\hline & $\mathbf{S}(\%)$ & $\mathbf{R}(\%)$ & $\mathbf{S}(\%)$ & $\mathbf{R}(\%)$ & $\mathrm{S}(\%)$ & $\mathbf{R}(\%)$ & $\mathbf{S}(\%)$ & $\mathbf{R}(\%)$ \\
\hline Azithromycin(30 $\mu \mathrm{g})$ & $22(79 \%)$ & $6(21 \%)$ & $4(67 \%)$ & $2(33 \%)$ & $5(63 \%)$ & $3(37 \%)$ & $1(100 \%)$ & $0(0 \%)$ \\
\hline Cefoxitin $(30 \mu \mathrm{g})$ & $17(61 \%)$ & $11(39 \%)$ & $4(67 \%)$ & $2(33 \%)$ & $5(63 \%)$ & $3(37 \%)$ & - & - \\
\hline Ciprofloxacin $(5 \mu \mathrm{g})$ & $12(43 \%)$ & $16(57 \%)$ & $3(50 \%)$ & $3(50 \%)$ & $3(38 \%)$ & $5(62 \%)$ & $1(100 \%)$ & $0(0 \%)$ \\
\hline Clindamycin $(2 \mu \mathrm{g})$ & $23(82 \%)$ & $5(18 \%)$ & $6(100 \%)$ & $0(0 \%)$ & $8(100 \%)$ & $0(0 \%)$ & $1(100 \%)$ & $0(0 \%)$ \\
\hline Tetracycline $(30 \mu \mathrm{g})$ & $24(86 \%)$ & $4(14 \%)$ & $5(83 \%)$ & $1(17 \%)$ & $6(75 \%)$ & $2(25 \%)$ & $1(100 \%)$ & $0(0 \%)$ \\
\hline Gentamycin $(10 \mu \mathrm{g})$ & $20(71 \%)$ & $8(29 \%)$ & $4(67 \%)$ & $2(33 \%)$ & $7(88 \%)$ & $1(12 \%)$ & - & - \\
\hline Linezolid (30 $\mu \mathrm{g})$ & $27(96 \%)$ & $1(4 \%)$ & $6(100 \%)$ & $0(0 \%)$ & $8(100 \%)$ & $0(0 \%)$ & $1(100 \%)$ & $0(0 \%)$ \\
\hline Penicillin-G(10units) & $1(4 \%)$ & $27(96 \%)$ & $0(0 \%)$ & $6(100 \%)$ & $2(25 \%)$ & $6(75 \%)$ & $0(0 \%)$ & $1(100 \%)$ \\
\hline 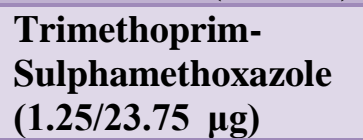 & $9(32 \%)$ & $19(68 \%)$ & $1(17 \%)$ & $5(83 \%)$ & $2(25 \%)$ & $6(75 \%)$ & - & - \\
\hline Vancomycin $(30 \mu \mathrm{g})$ & $28(100 \%)$ & $0(0 \%)$ & $6(100 \%)$ & $0(100 \%)$ & $8(100 \%)$ & $0(0 \%)$ & - & - \\
\hline
\end{tabular}


Table.4 Antibiotic sensitivity pattern of gram negative bacilli

\begin{tabular}{|c|c|c|c|c|c|c|c|c|c|c|c|c|c|c|c|c|}
\hline Antibiotics & K.p & neumor & $a e(n$ & $=17)$ & & E.coli & $n=1$ & & & Protel & $(n$ & & & Citroba & $\operatorname{er}($ & \\
\hline & $\mathbf{S}$ & $\%$ & $\mathbf{R}$ & $\%$ & $\mathbf{S}$ & $\%$ & $\mathbf{R}$ & $\%$ & $\mathbf{S}$ & $\%$ & $\mathbf{R}$ & $\%$ & $\mathbf{S}$ & $\%$ & $\mathbf{R}$ & $\%$ \\
\hline Amikacin $(30 \mu g)$ & 17 & $100 \%$ & & $0 \%$ & 12 & $75 \%$ & 4 & $25 \%$ & 2 & $100 \%$ & 0 & $0 \%$ & 2 & $67 \%$ & 1 & $33 \%$ \\
\hline $\begin{array}{l}\text { Amoxicillin- } \\
\text { clavulanic } \quad \text { acid } \\
(30 \mu \mathrm{g})\end{array}$ & 5 & $29 \%$ & 12 & $71 \%$ & 3 & $19 \%$ & 13 & $81 \%$ & 0 & $0 \%$ & 2 & $100 \%$ & 2 & $67 \%$ & 1 & $33 \%$ \\
\hline Aztreonam $(30 \mu \mathrm{g})$ & 11 & $65 \%$ & 6 & $35 \%$ & 14 & $88 \%$ & 2 & $13 \%$ & 2 & $100 \%$ & 0 & $0 \%$ & 2 & $67 \%$ & 1 & $33 \%$ \\
\hline $\begin{array}{l}\text { Ceftazidime } \\
(30 \mu \mathrm{g})\end{array}$ & 8 & $47 \%$ & 9 & $53 \%$ & 2 & $13 \%$ & 14 & $88 \%$ & 2 & $100 \%$ & 0 & $0 \%$ & 1 & $33 \%$ & 2 & $67 \%$ \\
\hline Cefuroxime $(30 \mu \mathrm{g})$ & 4 & $24 \%$ & 13 & $76 \%$ & 5 & $31 \%$ & 11 & $69 \%$ & 2 & $100 \%$ & 0 & $0 \%$ & 0 & $0 \%$ & 3 & $100 \%$ \\
\hline Cefazolin $(30 \mu \mathrm{g})$ & 5 & $29 \%$ & 12 & $71 \%$ & 1 & $6 \%$ & 15 & $94 \%$ & 2 & $100 \%$ & 0 & $0 \%$ & 0 & $0 \%$ & 3 & $100 \%$ \\
\hline Cefoxitin $(30 \mu \mathrm{g})$ & 9 & $53 \%$ & 8 & $47 \%$ & 13 & $81 \%$ & 3 & $19 \%$ & 0 & & 2 & $100 \%$ & 1 & $33 \%$ & 2 & $67 \%$ \\
\hline $\begin{array}{l}\text { Ceftazidime- } \\
\text { clavulanic } \\
(30 / 10 \mu \mathrm{g})\end{array}$ & 13 & $76 \%$ & 4 & $24 \%$ & 10 & $63 \%$ & 6 & $38 \%$ & 2 & $100 \%$ & 0 & $0 \%$ & 2 & $67 \%$ & 1 & $33 \%$ \\
\hline $\begin{array}{l}\text { Ciprofloxacin } \\
(5 \mu \mathrm{g})\end{array}$ & 15 & $88 \%$ & 2 & $12 \%$ & 13 & $81 \%$ & 3 & $19 \%$ & 2 & $100 \%$ & 0 & $0 \%$ & 1 & $33 \%$ & 2 & $67 \%$ \\
\hline Tobramycin $(10 \mu \mathrm{g})$ & 15 & $88 \%$ & 2 & $12 \%$ & 15 & $94 \%$ & 1 & $6 \%$ & 0 & & 2 & $100 \%$ & 3 & $100 \%$ & 0 & $0 \%$ \\
\hline Meropenem $(10 \mu \mathrm{g})$ & 17 & $100 \%$ & 0 & $0 \%$ & 17 & $100 \%$ & 0 & $0 \%$ & 2 & $100 \%$ & 0 & $0 \%$ & 3 & $100 \%$ & 0 & $0 \%$ \\
\hline $\begin{array}{l}\text { Piperacillin- } \\
\text { tazobactam } \\
(100 / 10 \mu \mathrm{g})\end{array}$ & 16 & $94 \%$ & 1 & $6 \%$ & 16 & $100 \%$ & 0 & $0 \%$ & 2 & $100 \%$ & 0 & $0 \%$ & 3 & $100 \%$ & 0 & $0 \%$ \\
\hline $\begin{array}{l}\text { Tetracycline } \\
(30 \mu \mathrm{g})\end{array}$ & 12 & $71 \%$ & 5 & $29 \%$ & 3 & $19 \%$ & 13 & $81 \%$ & 2 & $100 \%$ & 0 & $0 \%$ & 1 & $33 \%$ & 2 & $67 \%$ \\
\hline $\begin{array}{l}\text { Trimethoprim- } \\
\text { Sulphamethoxazole } \\
(1.25 / 23.75 \mu \mathrm{g})\end{array}$ & 1 & $6 \%$ & 16 & $94 \%$ & 1 & $6 \%$ & 15 & $94 \%$ & 2 & $100 \%$ & 0 & $0 \%$ & 1 & $33 \%$ & 2 & $67 \%$ \\
\hline
\end{tabular}

Table.5 Antibiotic sensitivity pattern of Pseudomonas isolates

\begin{tabular}{|l|c|c|c|c|}
\hline \multirow{2}{*}{ Antibiotics } & \multicolumn{4}{|c|}{ Pseudomonas (n=12) } \\
\cline { 2 - 5 } & $\mathbf{S}$ & $\mathbf{\%}$ & $\mathbf{R}$ & $\%$ \\
\hline Amikacin $(\mathbf{3 0} \boldsymbol{\mu g})$, & 11 & $92 \%$ & 1 & $8 \%$ \\
\hline Aztreonam $(\mathbf{3 0} \boldsymbol{\mu g})$ & 10 & $83 \%$ & 2 & $17 \%$ \\
\hline Ceftazidime $(\mathbf{3 0} \boldsymbol{\mu g})$ & 10 & $83 \%$ & 2 & $17 \%$ \\
\hline Ciprofloxacin $(\mathbf{5} \boldsymbol{\mu g})$ & 7 & $58 \%$ & 5 & $42 \%$ \\
\hline Gentamicin $(\mathbf{1 0} \boldsymbol{\mu g})$ & 11 & $92 \%$ & 1 & $8 \%$ \\
\hline Meropenem $(\mathbf{1 0} \boldsymbol{\mu g})$ & 12 & $100 \%$ & 0 & $0 \%$ \\
\hline Piperacillin-tazobactam $\mathbf{( 1 0 0 / 1 0} \boldsymbol{\mu g})$ & 12 & $100 \%$ & 0 & $0 \%$ \\
\hline
\end{tabular}


Fig.1 Pie chart showing culture positivity among pus sample

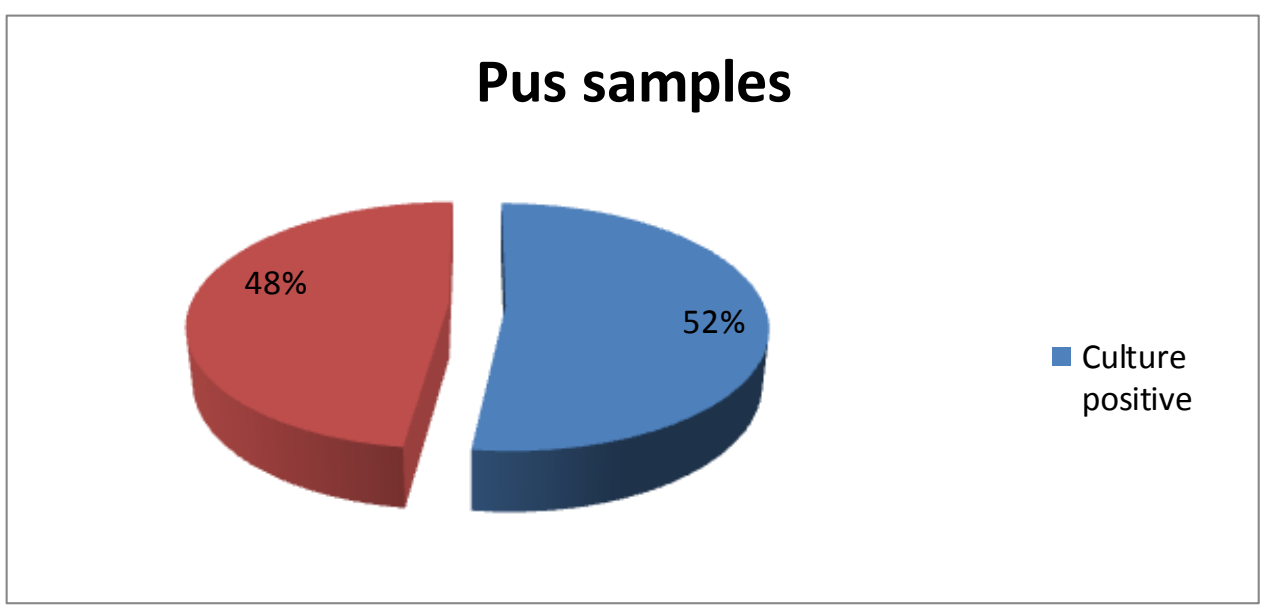

Fig.2 Distribution of aerobic bacterial isolates $(n=93)$ among the positive pus culture specimens

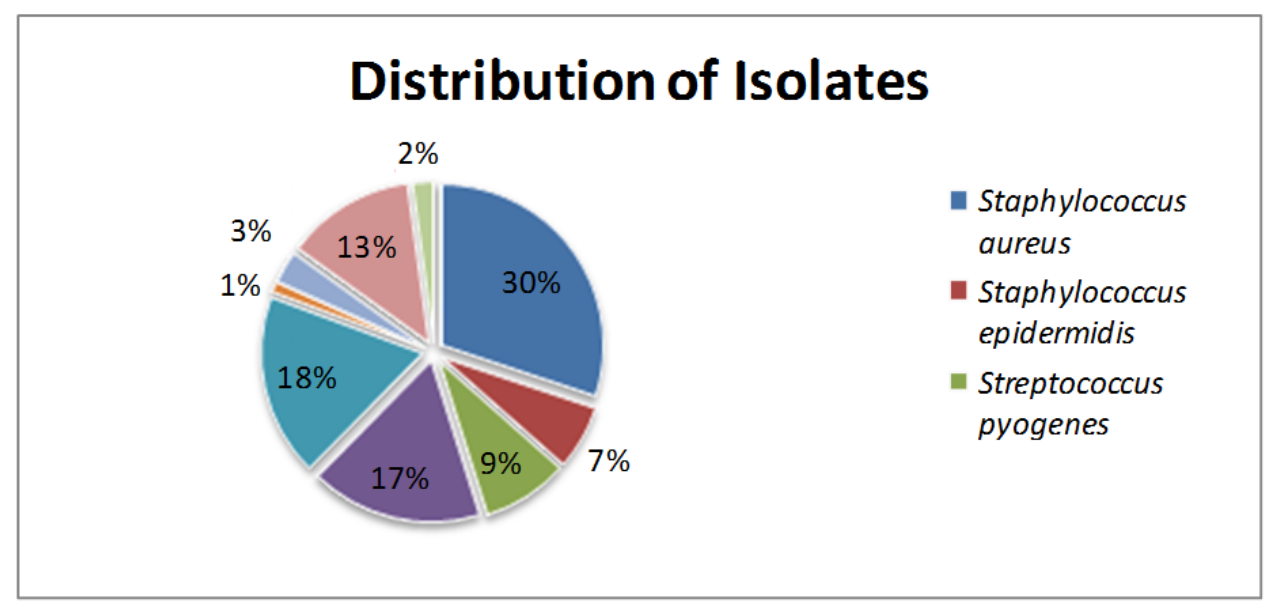

Fig.3 Showing MRSA isolates

\section{MRSA Isolates}

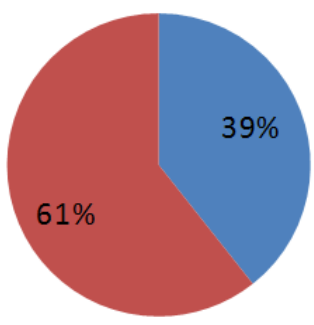

MRSA MSSA 
Fig.4 Showing ESBL producers among enterobacteriaceae

\section{ESBLs among Enterobacteriaceae \\ ESBL Non- ESBL}

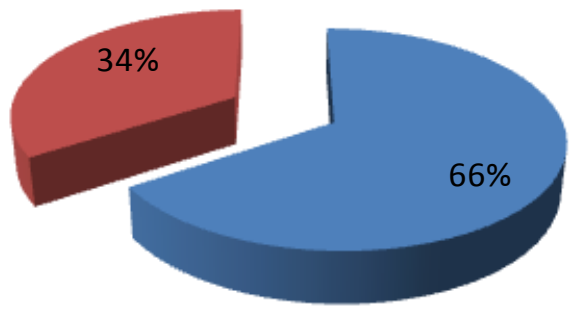

It is concluded that, in the clinical care setting, pyogenic infections are still a leading cause of morbidity following surgery and trauma. The most common bacteria isolated after aerobic culture of pus was Staphylococcus aureus. However, Gram negative bacilli have dominated Gram positive cocci as etiological agents of pyogenic infections. Among the GNB, Klebsiella pneumoniae is the most common bacteria causing these infections. The bacterial isolates showed a high degree of antimicrobial resistance. Knowledge of common pathogens and their resistance status can guide clinician to choose appropriate antibiotics for empirical treatment of patients. Hence, periodic review of the bacteriological profile and antibiotic sensitivity pattern is highly essential.

\section{References}

Agnihotri N., Gupta V, Joshi RM. 2004. Aerobic bacterial isolates from burn wound infections and their antibiograms -a five year study. Burns. 30(3): 241-3.

Bacteriological profile and Drug sensitivity pattern of Pus samples in a tertiary care hospital.

Bauer AW, Kirby WMM, Sherris JC, Turck
M. Antibiotic susceptibility testing by a standardized single disc method. Am. J. Clin. Pathol. 1966; 45: 493-496.

CLSI. Performance standard for Antimicrobial susceptibility testing. 2016; twenty third informational supplement. M100-S26: vol 33 no.1.

Cogen AL, Nizet V, Gallo RL. Skin microbiota: a source of disease or defense? British Journal of Dermatology 2008; 158(3): 442-455

Collee JG, Miles RS, Watt B. Mackie \& McCartney's practical medical microbiology 14th Ed. In: JG Collee, AG Fraser, BP Marmion, A Simmons, Editors. Churchill Livingstone: Indian Reprint; 2008.

Courvalin P. Antimicrobial drug resistance: prediction is very difficult, especially about the future. Emerg Infect Dis. 2005; 11: 1503-06.

El-Azizi M., Mushtaq A, Drake C, Lawhorn $\mathrm{J}$, Barenfanger J, Verhulst S, et al. Evaluating antibiograms to monitor drug resistance. Emerg Infect Dis. 2005.

Ghosh A., Karmakar PS, Pal J, Chakraborty N, Debnath NB, Mukherjee JD. Bacterial incidence and antibiotic sensitivity pattern in moderate and 
severe infections in hospitalized patients. J Indian Med Assoc 2009; 107(1): 21-2.

Int.J.Curr.Microbiol.App.Sci. 2016; 5(1):95102.

Iredell J., Brown J., Tagg K. Antibiotic resistance in Enterobacteriaceae: mechanisms and clinical implications. British Medical Journal 2016; 352.

Jeffrey Stone A., and Paul Cianci.Diabetic wounds. DiabetesSpectrum 1997; 4(2): 118-123.

Koneman WK., Allen SD, Janda WM, Schreckenberger PC, Propcop GW, Woods GL, Winn WC. Jr. Philadelphia Color Atlas and Textbook of Diagnostic Microbiology, 6th ed. Lippincott-Raven Publisher, 2005: 624-662.

Krige J.E.J., and Beckingham J.I. Liver abscesses and hydatid disease. BMJ 2001, 23; 322(7285): 537.

Neelima A., Praveen K, 2013. Bacteriological profile of wound infection in rural hospital in R.R district. Int. J Med Res Health Sci. 2(3): 469-473.

Perween N., Bharara T and Krishanprakash S. Bacteriological profile of pus and body fluid isolates and their antimicrobial susceptibility pattern. J Bacteriol Mycol. 2018; 5(1): 1060.

Pushpalatha Hanumanthappa, B. Vishalakshi and Krishna S. A Study on aerobic

Rao R., Basu R, Biswas DR. 2014. Aerobic bacterial profile and antimicrobial susceptibility pattern of pus isolates in a south Indian tertiary care hospital. Journal of Dental and Medical Sciences March; 13(3): 59-62.

Mohanty, S., A Kapil, B Dhawan, B K das.2004. Bacteriological and antimicrobial susceptibility profile of soft tissue infections from northern India Indian J Med Sci Vol. 58(1).

Scalise A., Bianchi A., Tartaglione C., et al. Microenvironment and microbiology of skin wounds: the role of bacterial biofilms and related factors. Seminars in Vascular Surgery 2015; 28(34):151-159 .

Shrestha, S., R. Amatya and R. Dutta. 2011. Prevalence of Extended spectrum beta lactamase production in gram negative isolates from pyogenic infection in tertiary care hospital of Eastern Nepal. Nepal Med Coll J; 13(3):186-189.

Subha, M. and Meerah Srinivasagam. 2018. Microbial profile and antimicrobial susceptibility pattern of pus culture isolates from a teaching tertiary care hospital, South India. Int.J.Curr.Microbiol.App.Sci. $\quad 7(04)$ : 1149-1153.

Sujatha R, Ankita Tripathi, Vineet, Nidhi Pal. 2016. Microbial characterisation of pus isolates and the changing trends in their sensitivity pattern at a tertiary care hospital in Kanpur City. RAMA Univ. J. Med Sci; 2(3):1-7.

\section{How to cite this article:}

Qader Ahmed Jalily, G. Sasikala and and Usha Rani Ramavath. 2019. Bacteriological Profiles of Pus with Antimicrobial Sensitivity Pattern at a Teaching Hospital in Vikarabad. Int.J.Curr.Microbiol.App.Sci. 8(07): 1556-1564. doi: https://doi.org/10.20546/ijcmas.2019.807.185 